\title{
Duodenal $L$ cell density correlates with features of metabolic syndrome and plasma metabolites
}

\author{
Annieke C G van Baar', Andrei Prodan², Camilla D Wahlgren ${ }^{3}$, Steen S Poulsen ${ }^{4,5}$, Filip K Knop ${ }^{3,5,6}$, \\ Albert K Groen ${ }^{2,7}$, Jacques J Bergman', Max Nieuwdorp2,8,9 and Evgeni Levin ${ }^{2,10}$ \\ 'Department of Gastroenterology and Hepatology, Academic Medical Center, Amsterdam, the Netherlands \\ 2Department of Vascular Medicine, Academic Medical Center, Amsterdam, the Netherlands \\ ${ }^{3}$ Center for Diabetes Research, Gentofte Hospital, University of Copenhagen, Copenhagen, Denmark \\ ${ }^{4}$ Department of Biomedical Sciences, Faculty of Health and Medical Sciences, University of Copenhagen, Copenhagen, Denmark \\ ${ }^{5}$ Novo Nordisk Foundation Center for Basic Metabolic Research, Faculty of Health and Medical Sciences, University of Copenhagen, \\ Copenhagen, Denmark \\ ${ }^{6}$ Department of Clinical Medicine, Faculty of Health and Medical Sciences, University of Copenhagen, Copenhagen, Denmark \\ ${ }^{7}$ Department of Laboratory Medicine, University of Groningen, University Medical Center, Groningen, the Netherlands \\ ${ }^{8}$ Department of Internal Medicine, VUMC Free University, Amsterdam, the Netherlands \\ ${ }^{9}$ Wallenberg Laboratory, Sahlgrenska Hospital, University of Gothenburg, Gothenburg, Sweden \\ ${ }^{10}$ Horaizon BV, Delft, the Netherlands \\ Correspondence should be addressed to A C G van Baar: a.c.vanbaar@amc.nl
}

\begin{abstract}
Background: Enteroendocrine cells are essential for the regulation of glucose metabolism, but it is unknown whether they are associated with clinical features of metabolic syndrome (MetS) and fasting plasma metabolites.

Objective: We aimed to identify fasting plasma metabolites that associate with duodenal $\mathrm{L}$ cell, $\mathrm{K}$ cell and delta cell densities in subjects with MetS with ranging levels of insulin resistance.

Research design and methods: In this cross-sectional study, we evaluated L, K and delta cell density in duodenal biopsies from treatment-naïve males with MetS using machinelearning methodology.

Results: We identified specific clinical biomarkers and plasma metabolites associated with $\mathrm{L}$ cell and delta cell density. L cell density was associated with increased plasma metabolite levels including symmetrical dimethylarginine, 3-aminoisobutyric acid, kynurenine and glycine. In turn, these L cell-linked fasting plasma metabolites correlated with clinical features of MetS.

Conclusions: Our results indicate a link between duodenal L cells, plasma metabolites and clinical characteristics of MetS. We conclude that duodenal L cells associate with plasma metabolites that have been implicated in human glucose metabolism homeostasis. Disentangling the causal relation between $L$ cells and these metabolites might help to improve the (small intestinal-driven) pathophysiology behind insulin resistance in human obesity.
\end{abstract}

Key Words
- metabolic syndrome
- incretins
- enteroendocrine cells
- plasma metabolites
- machine-learning
methodology

Endocrine Connections (2018) 7, 673-680

\section{Introduction}

The small intestinal mucosa orchestrates a complex response to a range of internal and external stimuli. A pivotal role is played by enteroendocrine cells, whose

http://www.endocrineconnections.org https://doi.org/10.1530/EC-18-0094

2018 The authors Published by Bioscientifica Ltd dysfunction has been linked to metabolic diseases such as obesity, metabolic syndrome (MetS) and type 2 diabetes (1). The gut incretin hormones, glucagon-like 
peptide-1 (GLP-1) and glucose-dependent insulinotropic polypeptide (GIP), produced by enteroendocrine L cells and $\mathrm{K}$ cells, respectively, are intimately involved in the regulation of glucose homeostasis (2). The early phase of postprandial GLP-1 secretion is likely mediated by the duodenal L cell population $(3,4)$. GLP-1 has an important glucoregulatory function and, notably, the incretin effect is reduced in subjects with type 2 diabetes (5). Rerouting of nutrients to L cell-rich parts of the gastrointestinal tract, as seen after gastric bypass surgery, enhances the postprandial GLP-1 responses (6), which in turn - like exogenous administration of GLP-1 receptor agonists (7) - improves glucose tolerance dramatically. L cells have a predominant location in the ileum but are present throughout the small intestine, whereas $\mathrm{K}$ cells are primarily located in the duodenum and proximal jejunum (8). On the other hand, somatostatin is produced by delta cells (D cells) in the gastrointestinal tract. Somatostatin reduces gastric acid production and slows down the digestive process by suppressing the release of GIP, insulin and glucagon. To date, it is not clear whether and how the densities of $\mathrm{L}, \mathrm{K}$ and $\mathrm{D}$ cells, respectively, are involved in the regulation of MetS features.

In this cross-sectional study, we aimed to identify plasma metabolites that associate with duodenal $\mathrm{L}$ cell, $\mathrm{K}$ cell and $\mathrm{D}$ cell densities in 38 subjects with MetS. To this end, we used recently published stateof-the-art statistical machine-learning methodology using an adapted version of the elastic net algorithm (9), specifically tailored for identification of the most relevant metabolite biomarkers (10).

\section{Materials and methods}

\section{Subjects}

We included 38 treatment-naïve obese male subjects with MetS (defined as $\geq 3$ out of 5 National Cholesterol Education Program criteria for MetS: fasting plasma glucose $\geq 5.6 \mathrm{mmol} / \mathrm{L}$; triglycerides $\geq 1.7 \mathrm{mmol} / \mathrm{L}$; waist circumference $>102 \mathrm{~cm}$; high-density cholesterol $<1.03 \mathrm{mmol} / \mathrm{L}$ and blood pressure $\geq 130 / 85 \mathrm{mmHg}$ ). Potential subjects who had a history of cholecystectomy, used a proton pump inhibitor, probiotics or antibiotics in the past 3 months were excluded. The study was approved by the Medical Ethical Committee of the Academic Medical Center Amsterdam in accordance with the Declaration of Helsinki. Written informed consent was obtained from all subjects preceding the screening visit to assess eligibility. During the screening visit, physical

$$
\text { http://www.endocrineconnections.org }
$$

examination was performed to assess height, body weight, waist and hip circumference and blood pressure. Blood was analyzed for hematology parameters, inflammatory markers, liver and kidney function, enzymes, lipids, shortchain fatty acids, gut hormones, glycemic parameters and glucose regulatory hormones. In eligible subjects, a mixed meal test was conducted and on a separate day, a gastroduodenoscopy was performed where duodenal biopsies were taken. These assessments were performed after an overnight fast.

\section{Mixed meal tolerance test and metabolites}

On the morning of admittance, a catheter was inserted into a forearm vein to obtain blood samples during the mixed meal tolerance test. A baseline (fasting) blood sample was taken first. Then, subjects ingested a liquid meal containing $616 \mathrm{kcal} / 2.6 \mathrm{MJ}$, containing $61 \%$ fat, $33 \%$ carbohydrate and protein 6\% (11). Blood was sampled for postprandial metabolism at every $30 \mathrm{~min}$ for $4 \mathrm{~h}$. These samples were analyzed for glucose, total GLP-1, GIP, peptide YY (PYY), primary and secondary bile acids and triglycerides. The area under the curve and incremental area under the curve were calculated for these parameters for up to $4 \mathrm{~h}$ after ingestion of the standardized meal. At baseline, plasma metabolites were determined by liquid chromatography-mass spectrometry for a panel of 96 metabolites containing either amines, oxidative stressors or lipids as previously described $(9,12,13,14)$.

\section{Duodenal biopsy samples}

A gastroenterologist at the Academic Medical Center Amsterdam performed a gastro-duodenoscopy to obtain postpapillary duodenal mucosal samples using a biopsy forceps. Biopsy material was immediately fixed in $4 \%$ buffered formaldehyde and immersed in this fixative for at least $18 \mathrm{~h}$. After fixation the tissues were embedded in paraffin. These samples were analyzed for histology to exclude structural abnormalities or pathology of the duodenal mucosa. The samples were cut in to sections of $5 \mu \mathrm{m}$ and dewaxed through xylene, alcohol and tap water. To retrieve antigens, sections were placed in a $10 \mathrm{mM}$ citrate buffer of $\mathrm{pH} 6$ and boiled in a microwave oven for $15 \mathrm{~min}$. Next, 10-min preincubation in $2 \%$ bovine serum albumin was performed ahead of overnight incubation at $4^{\circ} \mathrm{C}$ with a primary antibody. The following antibodies (mentioned in parentheses) were used for GLP-1 (GLPa, 1F5, 6-2-2006, 'in-house' 
mouse monoclonal, diluted 1:1500), GIP ((1-30) $\mathrm{NH}_{2}$ (95234-3), 10-4-96 'in-house', rabbit polyclonal, diluted 1:50,000) and somatostatin (somatostatin (1749-6), rabbit, diluted 1:30,000). The sections were incubated for 40 min with a second layer of antibodies to amplify the reaction. Biotinylated secondary immunoglobulins were used (goat anti-rabbit: BA-1000 (Vector Laboratories, Burlingame, CA, USA) for GIP and somatostatin and horse anti-mouse: BA-2000 (Vector Laboratories) for GLP-1; all diluted 1:200). Next, hydrogenperoxide 3\% was added to block endogenous peroxidase. The third layer consists of a preformed avidin and biotinylated horseradish peroxidase macromolecular complex (Vector Laboratories, code nr. PK-4000) and was incubated for $30 \mathrm{~min}$. The reaction was developed by the use of 3.3-diaminobenzidine (KEM-EN-TEC Diagnostics, Taastrup, Denmark, cat. no. 4170) for $15 \mathrm{~min}$, followed by 2 -min incubation in $0.5 \%$ copper sulfate (Merck, art. no. 2790) diluted in Tris buffer $0.05 \%$ with Tween 20 (DAKO, S1966). Finally, counterstaining with Mayers Hemalum (Merck) was performed.

The distribution of enteroendocrine cells was evaluated from biopsy slide sections based on immunohistochemical staining (Fig. 1). Digital images of biopsy slides were obtained using Aperio ScanScope scanner with a 20× objective. The newCAST system (Visiopharm, Hørsholm, Denmark) was used to estimate enteroendocrine cell density within the complete individual biopsy slide sections containing both villi and crypts. The size of epithelium and total biopsy area were obtained using a prespecified grid and point-counting technique; the number of + points 'hitting' a structure of interest was multiplied with the area per+point yielding the total area. Next, the number of all immunopositive (stained) cells within the epithelium was counted and divided by the size of the epithelium, thus providing an estimation of cell density.

\section{Statistical analysis}

SPSS, version 23 was used to summarize the baseline characteristics of both the subjects and to describe the duodenal biopsies. Continuous variables are summarized utilizing descriptive statistics. An elastic net regularized regression model (15) with stability selection (16) was implemented in Python 2.7 (www.python.org) as a feature selection tool. All data (predictor features as well as the predicted variable) were scaled to zero mean and unit variance. To train each model, the two hyperparameters (the alpha - the size of the regularization penalty and the L1 ratio - the ratio of L1-norm/L2-norm in the model penalty) were optimized using a 5 -fold crossvalidation procedure on a subset comprising $80 \%$ of the data. The model was then tested on the remaining $20 \%$ of the data not used in the training. This procedure was repeated 100 times per analysis, each time using different random splitting of the data into training and test subsets. The stability of each feature was calculated as the number of times (out of 100) the respective feature was kept by the model (i.e. the number of times out of 100 runs that the feature had a non-zero regression coefficient. See the architecture of the elastic net model with stability selection workflow in Fig. 2). For each analysis, the top four features with the highest stabilities were selected, providing their stability coefficient was higher than a preset threshold. Stability thresholds were $60 \%$ for models using baseline metabolites to predict $\mathrm{L}$ cell/K cell/D cell density ('primary models') and 33\% for models using fasting plasma measurements and other clinical measurements to predict L cell-linked metabolites ('secondary models'). Permutation testing (1000 permutations) (17) was performed to assess the significance of the link of the selected feature/feature set with the respective predicted variable. Permutation testing was performed by rerunning the model with only the selected features on a random

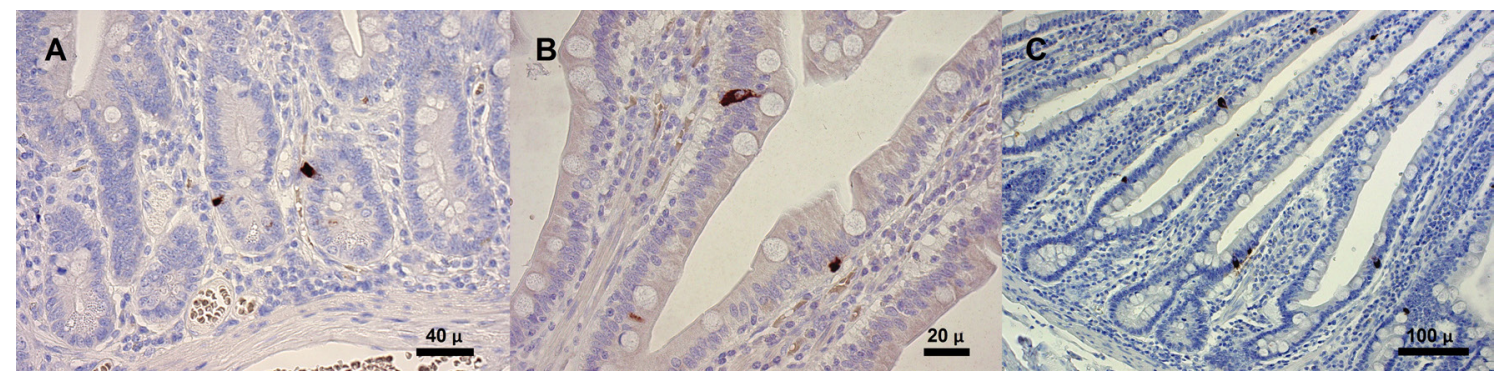

\section{Figure 1}

Immunopositive cells stained for (A) GIP (K cells), (B) GLP-1 (L cells) and (C) somatostatin (D cells). GIP, glucose-dependent insulinotropic polypeptide; GLP-1, glucagon-like peptide-1. Scale bar included in each panel separately.

$$
\begin{aligned}
& \text { http://www.endocrineconnections.org } \\
& \text { http://doi.org/10.1530/EC-18-0094 }
\end{aligned}
$$




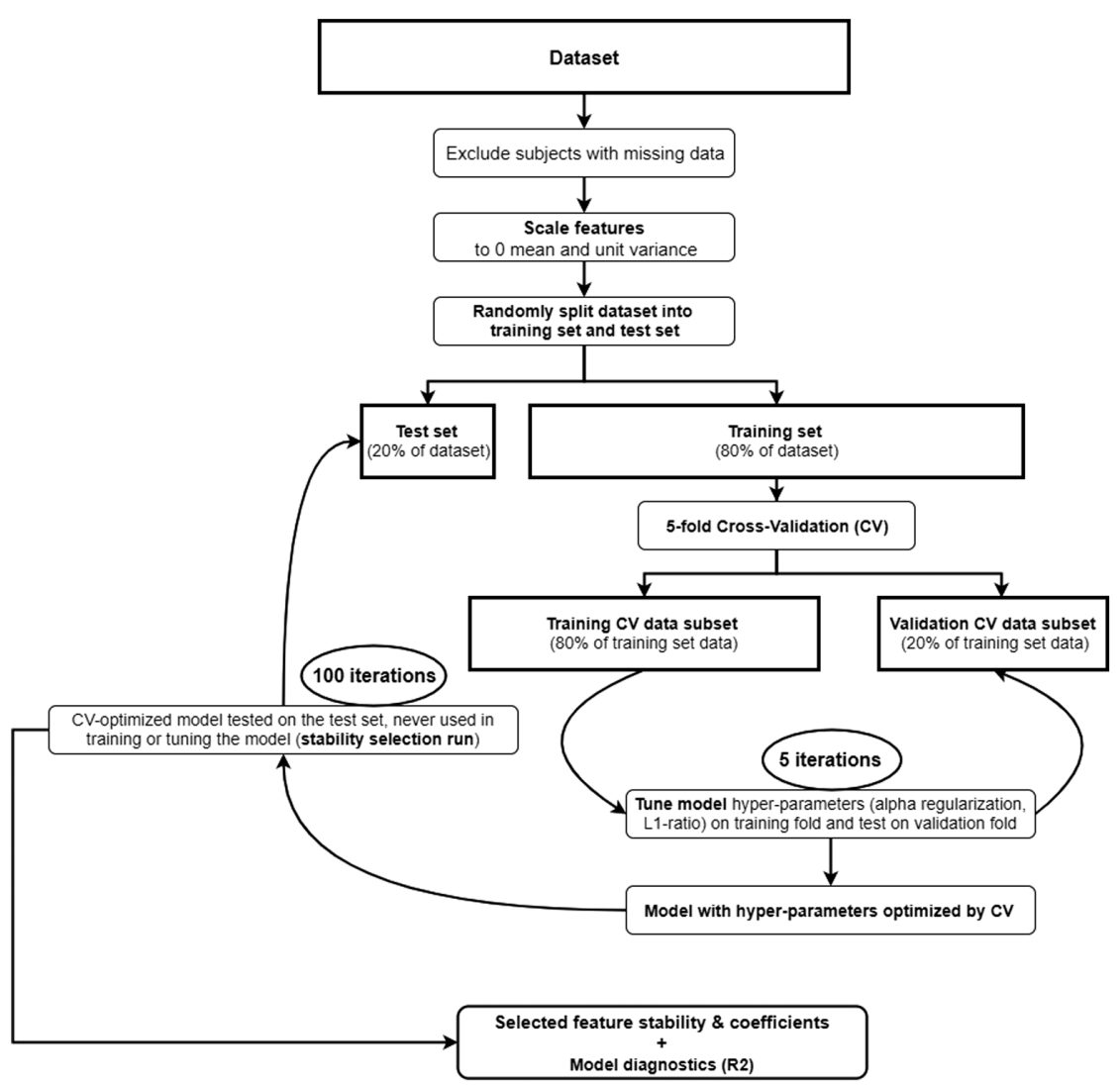

Figure 2

Elastic net flowchart. train/test data split, and comparing the resulting (true) model $R^{2}$ with the (permuted) model $R^{2}$ s of 1000 models trained and tested on the same train/test data subsets, with the same hyperparameter ranges as the real model, but with randomly shuffled labels of the predicted variable prior to training. For selected features, the Spearman correlation was calculated between the respective feature and its predicted variable. The detailed architecture of the elastic net model with stability selection workflow is schematically displayed in Fig. 2.

\section{Results}

In total, 38 male MetS subjects were included from our previously published study (9) in which we collected duodenal biopsies. All biopsies showed normal histology. Baseline characteristics are shown in Table 1. On average, the mean epithelial area of the duodenal biopsies was $0.66 \pm 0.30 \mathrm{~mm}^{2}$ and the total area of the biopsies was $1.65 \pm 0.63 \mathrm{~mm}^{2}$. Mean cell density of $\mathrm{K}, \mathrm{L}$ and $\mathrm{D}$ cells are shown in Table 2. Results of the mixed meal tolerance test (glucose, GLP-1, GIP and PYY) can be appreciated from Supplementary Fig. 1 (see section on supplementary data given at the end of this article).

$$
\begin{aligned}
& \text { http://www.endocrineconnections.org } \\
& \text { https://doi.org/10.1530/EC-18-0094 }
\end{aligned}
$$

O2018 The authors Published by Bioscientifica Ltd
Upon multivariate modeling using the elastic net model, we found that duodenal L cell density was associated with increased fasting plasma metabolite levels of symmetrical dimethylarginine (SDMA),

\begin{tabular}{|c|c|c|c|c|}
\hline Subject characteristics & Mean & S.D. & Median & $\begin{array}{c}\text { Inter } \\
\text { quartile } \\
\text { range }\end{array}$ \\
\hline Age (years) & 54 & 7 & 54 & 8 \\
\hline BMI $\left(\mathrm{kg} / \mathrm{m}^{2}\right)$ & 35 & 3.6 & 34.2 & 5.2 \\
\hline Waist circumference $(\mathrm{cm})$ & 121 & 9 & 120 & 14 \\
\hline $\begin{array}{l}\text { Systolic blood pressure } \\
(\mathrm{mmHg})\end{array}$ & 145 & 18 & 142 & 23 \\
\hline $\begin{array}{l}\text { Diastolic blood pressure } \\
(\mathrm{mmHg})\end{array}$ & 90 & 12 & 91 & 18 \\
\hline $\mathrm{HbA} 1 \mathrm{c}(\mathrm{mmol} / \mathrm{mol})$ & 40 & 7 & 40 & 7 \\
\hline HbA1c (\%) & 5.8 & 0.6 & 5.8 & 0.6 \\
\hline Fasting glucose (mmol/L) & 5.9 & 0.9 & 5.6 & 0.9 \\
\hline Fasting insulin (pmol/L) & 121 & 48 & 117 & 46 \\
\hline Total cholesterol (mmol/L) & 5.65 & 1.08 & 5.48 & 2.07 \\
\hline HDL cholesterol (mmol/L) & 1.15 & 0.26 & 1.06 & 0.36 \\
\hline LDL cholesterol (mmol/L) & 3.88 & 0.94 & 3.80 & 1.75 \\
\hline Triglycerides (mmol/L) & 1.45 & 0.65 & 1.25 & 0.69 \\
\hline HOMA-IR & 4.53 & 1.95 & 4.36 & 2.18 \\
\hline
\end{tabular}

Table 1 Subject baseline characteristics.

BMI, body mass index; HbA1c, glycated hemoglobin A1c; HDL, highdensity lipoprotein; HOMA-IR, homeostatic model assessment-insulin resistance; LDL, low-density lipoprotein.

This work is licensed under a Creative Commons Attribution-NonCommercial-NoDerivatives 4.0 International License. 
Table 2 Characteristics duodenal biopsies.

\begin{tabular}{|c|c|c|c|c|}
\hline $\begin{array}{l}\text { Duodenal biopsy } \\
\text { characteristics }\end{array}$ & Mean & S.D. & Median & $\begin{array}{c}\text { Inter } \\
\text { quartile } \\
\text { range }\end{array}$ \\
\hline Length $(\mathrm{mm})$ & 3.47 & 0.84 & 3.30 & 1.08 \\
\hline Area epithelium $\left(\mathrm{mm}^{2}\right)$ & 0.66 & 0.30 & 0.50 & 0.42 \\
\hline Total area biopsy $\left(\mathrm{mm}^{2}\right)$ & 1.65 & 0.63 & 1.60 & 1.01 \\
\hline $\begin{array}{l}\text { L cell density (cells } / \mathrm{mm}^{2} \\
\text { epithelium) }\end{array}$ & 10 & 8 & 10 & 13 \\
\hline $\begin{array}{l}\text { K cell density (cells/mm² } \\
\text { epithelium) }\end{array}$ & 57 & 26 & 56 & 34 \\
\hline $\begin{array}{l}\text { D cell density (cells/mm² } \\
\text { epithelium) }\end{array}$ & 60 & 35 & 55 & 27 \\
\hline
\end{tabular}

3-aminoisobutyric acid (BAIBA), kynurenine and glycine (model $R^{2}=0.294, P=0.017$ ). The plasma metabolite SDMA correlated most significantly with L cell density (stability 94\%) followed by BAIBA (stability 78\%). These plasma metabolites were also significantly associated
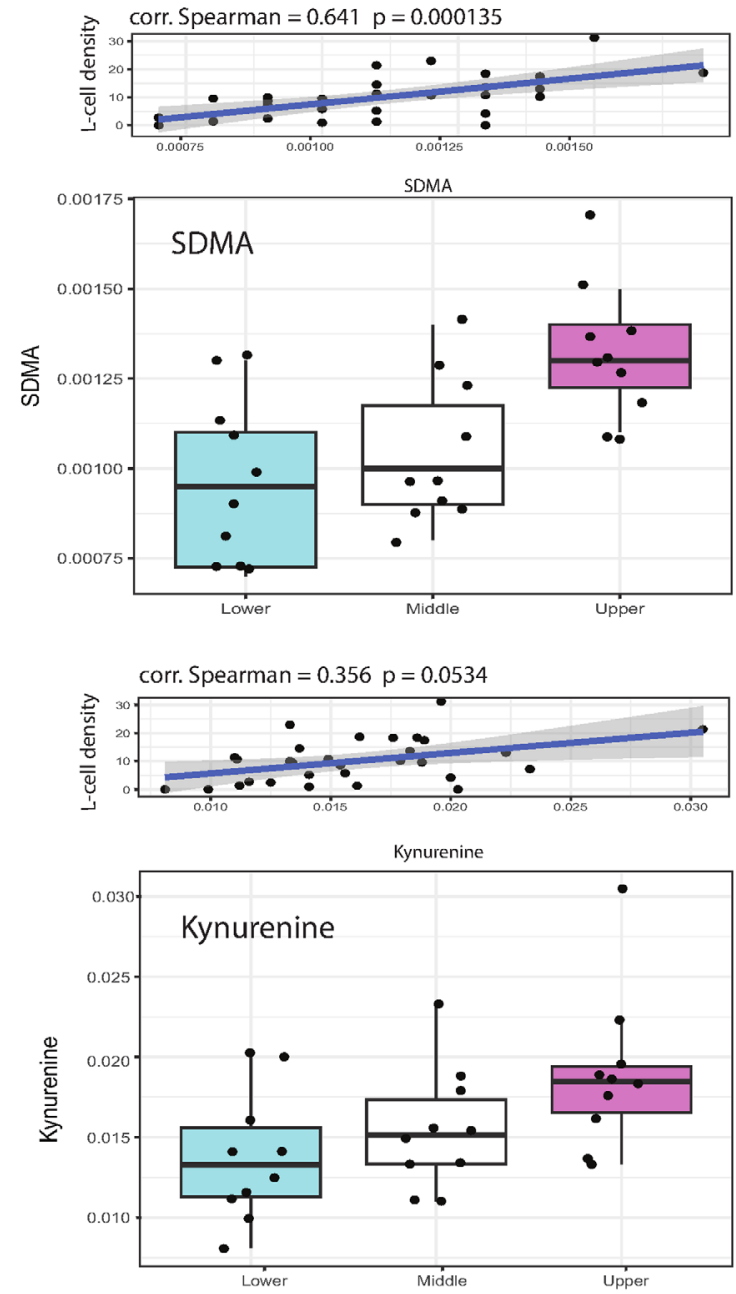

with the L cell density individually (Fig. 3). We did not find a significant direct correlation between duodenal L cell density and postprandial GLP-1 levels or clinical MetS features. D cells were linked to fasting BAIBA levels (Spearman correlation $0.38, P=0.0499$, stability 62\%). In contrast, we found no associations between duodenal $\mathrm{K}$ cell density and circulating metabolites.

We subsequently divided our study subjects based on duodenal L cell density tertiles and found that indeed the upper tertile displayed the strongest correlation with the abovementioned metabolites (Fig. 3).

We then studied the relation between the discovered biomarker plasma metabolites (SDMA, BAIBA, kynurenine and glycine) and duodenal incretin-producing cells and clinical markers. SDMA correlated significantly with plasma creatinine levels (model $R^{2}=0.224, P=0.019$ ). We found a negative correlation between kynurenine
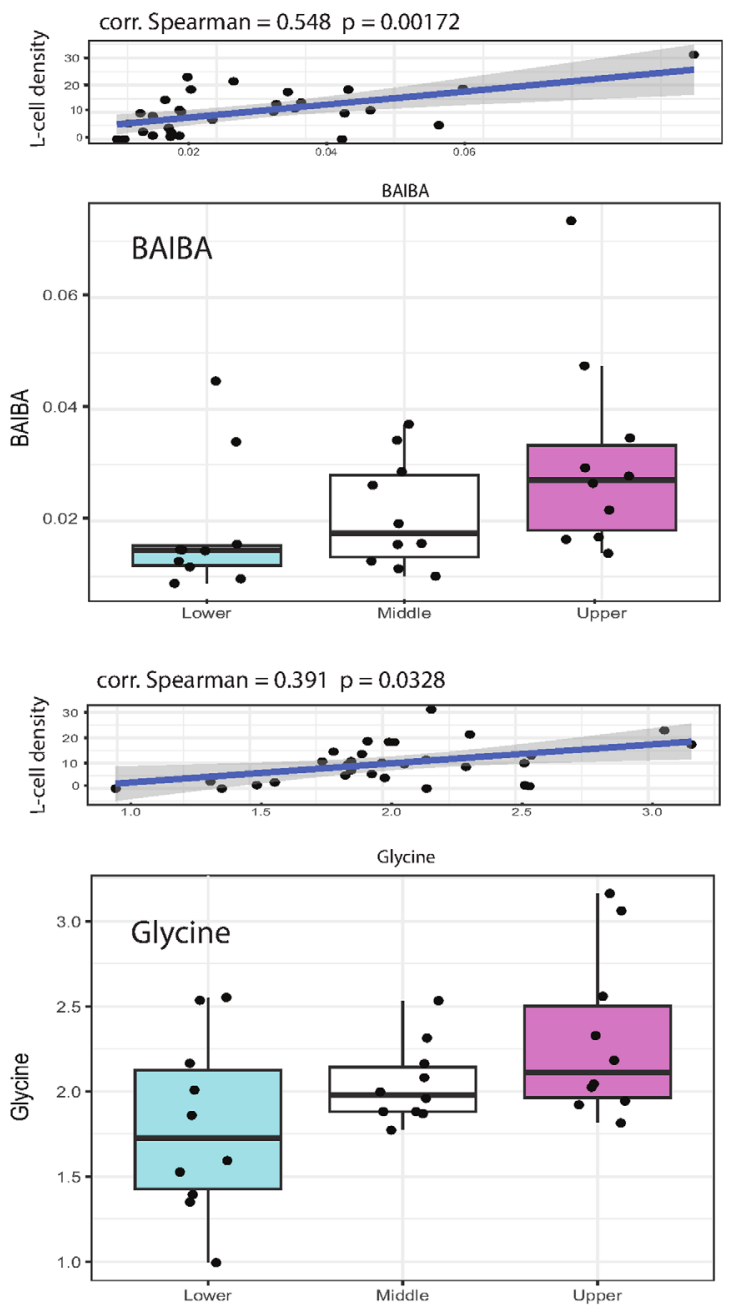

Figure 3

$\mathrm{L}$ cell-linked metabolites. Scatterplots with $\mathrm{L}$ cell density (cells $/ \mathrm{mm}^{2}$ epithelium) on $x$-axis and metabolite quantification on $y$-axis with depicted below the boxplots with classification by $L$ cell density tertiles and metabolite quantification on $y$-axis.

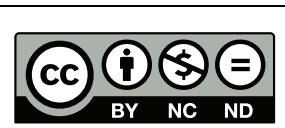

This work is licensed under a Creative Commons Attribution-NonCommercial-NoDerivatives 4.0 International License. 


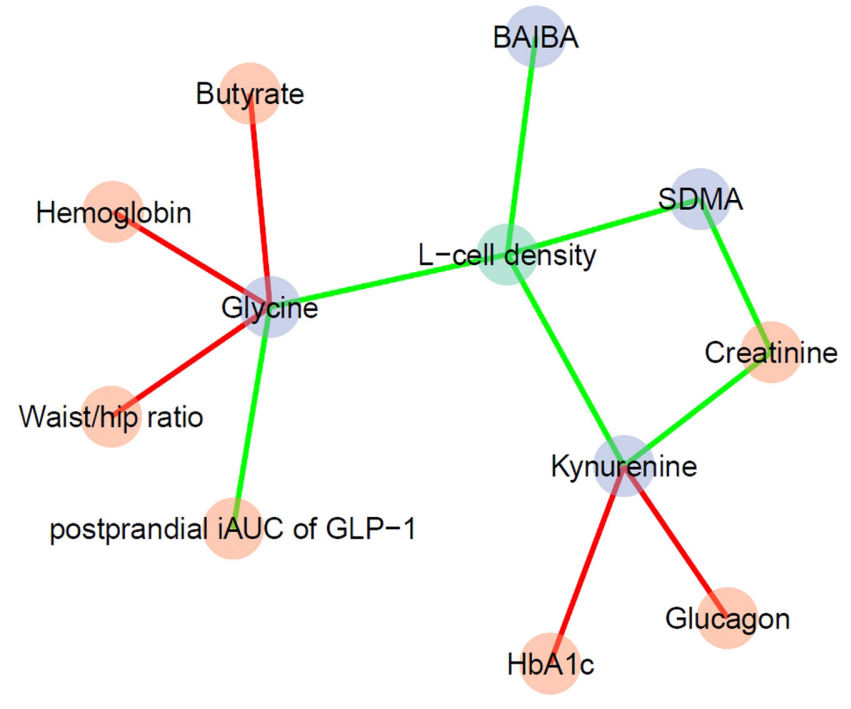

Figure 4

Correlation network with L cells (green), clinical MetS characteristics (pink) and plasma metabolites (blue). Red lines indicate a negative correlation between the two connecting variables. Green lines indicate a positive correlation. BAIBA, 3-aminoisobutyric acid; SDMA, symmetrical dimethylarginine; iAUC, incremental area under the curve; GLP-1, glucagon-like peptide-1; HbA1c, glycated hemoglobin A1c.

and glucagon and glycated hemoglobin (HbA1c), but a positive correlation with kynurenine and creatinine (overall model $R^{2}=0.353, P=0.004$ ). Glycine was negatively associated with hemoglobin, butyrate and waist-hip ratio. The postprandial GLP-1 response (incremental area under the curve) correlated with glycine with $85 \%$ stability (model $R^{2}=0.514, P=0.024$ ). We found no significant correlation with BAIBA and clinical characteristics. These links are schematically represented in Fig. 4. Except GLP-1, we found no other links between postprandial hormone levels and the discovered biomarker plasma metabolites.

\section{Discussion}

In this study, we show that enteroendocrine cell density in the epithelium of the duodenal mucosal varies between subjects with MetS and associates with specific fasting plasma metabolites and markers of glucose homeostasis. In turn, L cell-linked metabolites correlate with clinical features of MetS in our study population. Despite being much more numerous in the duodenum, we found only a single metabolite correlating with $\mathrm{D}$ cells and no correlation between $\mathrm{K}$ cells and plasma metabolites. Analysis describing duodenal L, K and D cell density indices and correlating these to circulating metabolites

$$
\text { http://www.endocrineconnections.org }
$$

and features of MetS have never been published before to our knowledge. Our findings indicate a link between duodenal L cells and metabolites and clinical features of MetS. We discover that SDMA, BAIBA, kynurenine and glycine together are linked to L cell density, as shown by rigorous multivariate analysis of the data. Below, we hypothesize on mechanisms relating $\mathrm{L}$ cell density to the observed clinical and metabolite parameters in MetS (links in Fig. 4).

L cell density correlated strongest with SDMA. This metabolite was reported to decrease in subjects with poor glycemic control (18). In our study, we found a positive correlation between SDMA and duodenal L cell density, which indicates that both SDMA and duodenal L cell density increase in subjects with improved glycemic control. SDMA is eliminated via the kidneys (18), which explains the correlation with plasma creatinine levels observed in our study.

Similarly to SDMA, BAIBA is also associated with improved glycemic control since BAIBA administration improves glucose tolerance (19). We found higher fasting plasma levels of BAIBA in subjects with higher L cell and D cell density but, in contrast to earlier reports, we found no association between clinical features of MetS and BAIBA levels.

Circulating glycine levels are inversely associated with type 2 diabetes risk (19) and plasma glycine levels rise with improved glucose homeostasis (20). As in the case of SDMA and BAIBA, subjects with high glycine levels are metabolically healthier than subjects in which levels of this metabolite are low. Since SDMA, BAIBA and glycine correlated with L cell density, a higher L cell density may be associated with ameliorated glycemic control. At the same time, the hypothetical possibility of dysfunctional L cells cannot be ignored.

We found a negative association between glycine and hemoglobin and waist-hip ratio. Subjects with type 2 diabetes and MetS have higher hemoglobin levels due to increased iron absorption (21). Higher L cell density and higher glycine levels indicate a healthier phenotype, supported by lower hemoglobin levels and lower waist-hip ratio. The postprandial GLP-1 response was linked to glycine, which in turn correlated with $\mathrm{L}$ cell density. This finding supports the importance of $\mathrm{L}$ cells, especially in subjects with MetS. Interestingly, we found a negative correlation between plasma glycine and butyrate levels. Plasma butyrate levels are usually decreased in MetS subjects due to a lower amount of intestinal butyrate production (22). Since the L cell density-linked metabolite glycine is reported to be 
higher in subjects with improved glucose homeostasis, we suggest that the duodenal L cell density increases to compensate for MetS metabolic impairment, as reflected by a decreased butyrate level. This might in turn cause a rise in SDMA, BAIBA and glycine levels, the aforementioned markers of improved glycemic control. We did not find direct links between L cell density and postprandial GLP-1 levels or L cell density and clinical MetS characteristics. This is possibly attributable to the relatively small and homogeneous study population and the cross-sectional nature of this study. Although we did not demonstrate such links with L cell density in our cross-sectional study, it is still possible that L cell density increases following deterioration of MetS, which can in turn improve glycemic control. However, such a series of events can only be detected by taking multiple duodenal biopsies in the course of deterioration (or improvement) of MetS.

Kynurenine was previously found to be increased in subjects with obesity and type 2 diabetes. Kynurenine overproduction is induced by chronic inflammation, one of the mechanisms promoting development of type 2 diabetes (23). We found a positive correlation between duodenal L cell density and kynurenine. Proliferation of L cells may be a physiological response to compensate for the disadvantageous effects of chronic inflammation, as indicated by the correlation between L cell density and kynurenine levels in our study. The negative correlation between kynurenine and HbA1c and glucagon in this study can be due to a kynurenine-driven induction of L cell proliferation, which could potentially improve glycemic control (23). Moreover, it would be interesting to be able to increase the duodenal L cell density or to amplify L cell activation (4) in vivo (e.g. using organoids) with the aim of improving glucose regulation. This might also include procedures aimed at specific activation of the duodenal mucosa (24). Such a procedure would allow us to investigate the causal relationship between duodenal $\mathrm{L}, \mathrm{K}$ and $\mathrm{D}$ cell density, metabolites and improvement or deterioration of MetS and type 2 diabetes. Until then, we conclude that small intestinal incretin-producing cells are involved in human glucose metabolism homeostasis via specific plasma metabolites. Disentangling such relations might help to improve the (small intestinaldriven) pathophysiology behind insulin resistance in human obesity.

\section{Supplementary data}

This is linked to the online version of the paper at https://doi.org/10.1530/ EC-18-0094.

\section{Declaration of interest}

The authors declare that there are no potential conflicts of interest relevant to the research reported.

\section{Funding}

M N is supported by a ZONMW-VIDI grant $2013(016.146 .327)$ and a Dutch Heart Foundation CVON Young Talent Grant 2013 (on which A P is appointed).

\section{Guarantor's statement}

Evgeni Levin is the guarantor of this work and, as such, had full access to all the data in the study and takes responsibility for the integrity of the data and the accuracy of the data analysis.

\section{Author contribution statement}

$A$ B designed the study (together with $M N$ ), analyzed and interpreted the data, performed statistical analysis and drafted the manuscript. A P analyzed data, performed statistical analysis and drafted the manuscript together with A B. CW acquired data and critically revised the manuscript. $\mathrm{S} \mathrm{P}$ contributed to the study design and performed critical revision of the manuscript for important intellectual content. F K contributed to the study design and performed critical revision of the manuscript for important intellectual content. A G performed study supervision, interpreted the data and performed critical revision of the manuscript for important intellectual content. J B acquired data and performed critical revision of the manuscript for important intellectual content. $\mathrm{M} \mathrm{N}$ designed the study together with A B, performed study supervision, interpreted the data and performed critical revision of the manuscript for important intellectual content. E L performed study supervision, performed statistical analysis, drafted the manuscript together with $A B$ and $A$ P and performed critical revision of the manuscript for important intellectual content. All authors approved the final version for publication.

\section{References}

1 Holst JJ, Pedersen J, Wewer Albrechtsen NJ \& Knop FK. The gut: a key to the pathogenesis of type 2 diabetes? Metabolic Syndrome and Related Disorders 201715 259-262. (https://doi.org/10.1089/ met.2017.0015)

2 Campbell JE \& Drucker DJ. Pharmacology, physiology, and mechanisms of incretin hormone action. Cell Metabolism 201317 819-837. (https://doi.org/10.1016/j.cmet.2013.04.008)

3 Theodorakis MJ, Carlson O, Michopoulos S, Doyle ME, Juhaszova M, Petraki K \& Egan JM. Human duodenal enteroendocrine cells: source of both incretin peptides, GLP-1 and GIP. American Journal of Physiology: Endocrinology and Metabolism 2006290 E550-E559. (https://doi.org/10.1152/ajpendo.00326.2004)

4 Sun EW, de Fontgalland D, Rabbitt P, Hollington P, Sposato L, Due SL, Wattchow DA, Rayner CK, Deane AM, Young RL, et al. Mechanisms controlling glucose-induced GLP-1 secretion in human small intestine. Diabetes 201766 2144-2149. (https://doi. org/10.2337/db17-0058)

5 Nauck M, Stockmann F, Ebert R \& Creutzfeldt W. Reduced incretin effect in type 2 (non-insulin-dependent) diabetes. Diabetologia 1986 29 46-52. (https://doi.org/10.1007/BF02427280)

6 Rhee NA, Vilsboll T \& Knop FK. Current evidence for a role of GLP-1 in Roux-en-Y gastric bypass-induced remission of type 2 diabetes. Diabetes, Obesity and Metabolism 201214 291-298. (https://doi. org/10.1111/j.1463-1326.2011.01505.x)

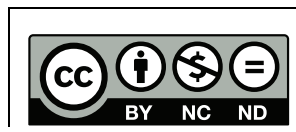

This work is licensed under a Creative Commons Attribution-NonCommercial-NoDerivatives 4.0 International License. 
7 Vilsboll T, Christensen M, Junker AE, Knop FK \& Gluud LL. Effects of glucagon-like peptide-1 receptor agonists on weight loss: systematic review and meta-analyses of randomised controlled trials. BMJ 2012 344 d7771. (https://doi.org/10.1136/bmj.d7771)

8 Jorsal T, Rhee NA, Pedersen J, Wahlgren CD, Mortensen B, Jepsen SL, Jelsing J, Dalbøge LS, Vilmann P, Hassan H, et al. Enteroendocrine K and L cells in healthy and type 2 diabetic individuals. Diabetologia 201761 284-294. (https://doi.org/10.1007/s00125-017-4450-9)

9 Kootte RS. Improvement of insulin sensitivity after lean donor fecal microbiota transplantation in metabolic syndrome subjects is associated with baseline intestinal microbiota composition. Cell Metabolism 201726 611.e6-619.e6. (https://doi.org/10.1016/j. cmet.2017.09.008)

10 Botschuijver S, Roeselers G, Levin E, Jonkers DM, Welting O, Heinsbroek SE, de Weerd HH, Boekhout T, Fornai M, Masclee AA, et al. Intestinal fungal dysbiosis associates with visceral hypersensitivity in patients with irritable bowel syndrome and rats. Gastroenterology 2017153 1026-1039. (https://doi.org/10.1053/j. gastro.2017.06.004)

11 Reijnders D, Goossens GH, Hermes GD, Neis EP, van der Beek CM, Most J, Holst JJ, Lenaerts K, Kootte RS, Nieuwdorp M, et al. Effects of gut microbiota manipulation by antibiotics on host metabolism in obese humans: a randomized double-blind placebo-controlled trial. Cell Metabolism 201624 63-74. (https://doi.org/10.1016/j. cmet.2016.06.016)

$12 \mathrm{Fu}$ J, Schoeman JC, Harms AC, van Wietmarschen HA, Vreeken RJ, Berger R, Cuppen BVJ, Lafeber FPJG, van der Greef J \& Hankemeier T. Metabolomics profiling of the free and total oxidised lipids in urine by LC-MS/MS: application in patients with rheumatoid arthritis. Analytical and Bioanalytical Chemistry 2016408 6307-6319. (https:// doi.org/10.1007/s00216-016-9742-2)

13 Noga MJ, Dane A, Shi S, Attali A, van Aken H, Suidgeest E, Tuinstra T, Muilwijk B, Coulier L, Luider T, et al. Metabolomics of cerebrospinal fluid reveals changes in the central nervous system metabolism in a rat model of multiple sclerosis. Metabolomics 20128 253-263. (https://doi.org/10.1007/s11306-011-0306-3)

14 Hu C, van Dommelen J, van der Heijden R, Spijksma G, Reijmers TH, Wang M, Slee E, Lu X, Xu G, van der Greef J, et al. RPLC-ion-trapFTMS method for lipid profiling of plasma: method validation and application to p53 mutant mouse model. Journal of Proteome Research 20087 4982-4991. (https://doi.org/10.1021/pr800373m)
15 Zou H \& Hastie T. Regularization and variable selection via the elastic net. Journal of the Royal Statistical Society: Series B (Statistical Methodology) 200567 301-320. (https://doi.org/10.1111/j.14679868.2005.00503.x)

16 Meinshausen N \& Bühlmann P. Stability selection. Journal of the Royal Statistical Society: Series B (Statistical Methodology) 201072 417-473. (https://doi.org/10.1111/j.1467-9868.2010.00740.x)

17 Golland P, Liang F, Mukherjee S \& Panchenko D. Permutation tests for classification. In Proceedings of the 18th Annual Conference on Learning Theory, pp 501-515. Bertinoro, Italy: Springer-Verlag, 2005. (https://doi.org/10.1007/11503415_34)

18 Can A, Bekpinar S, Gurdol F, Tutuncu Y, Unlucerci Y \& Dinccag N. Dimethylarginines in patients with type 2 diabetes mellitus: relation with the glycaemic control. Diabetes Research and Clinical Practice 201194 e61-e64. (https://doi.org/10.1016/j.diabres.2011.08.008)

19 Guasch-Ferre M, Hruby A, Toledo E, Clish CB, MartinezGonzalez MA, Salas-Salvado J \& Hu FB. Metabolomics in prediabetes and diabetes: a systematic review and meta-analysis. Diabetes Care 201639 833-846. (https://doi.org/10.2337/dc15-2251)

20 Yan-Do R \& MacDonald PE. Impaired 'glycine'-mia in type 2 diabetes and potential mechanisms contributing to glucose homeostasis. Endocrinology 2017158 1064-1073. (https://doi.org/10.1210/ en.2017-00148)

21 Jin Y, He L, Chen Y, Fang Y \& Yao Y. Association between serum ferritin levels and metabolic syndrome: an updated meta-analysis. International Journal of Clinical and Experimental Medicine $2015 \mathbf{8}$ 13317-13322.

22 Vrieze A, Van Nood E, Holleman F, Salojarvi J, Kootte RS, Bartelsman JF, Dallinga-Thie GM, Ackermans MT, Serlie MJ, Oozeer R, et al. Transfer of intestinal microbiota from lean donors increases insulin sensitivity in individuals with metabolic syndrome. Gastroenterology 2012143 913.e7-916.e7. (https://doi.org/10.1053/j. gastro.2012.06.031)

23 Cervenka I, Agudelo LZ \& Ruas JL. Kynurenines: Tryptophan's metabolites in exercise, inflammation, and mental health. Science 2017357 eaaf9794. (https://doi.org/10.1126/science.aaf9794)

24 Rajagopalan H, Cherrington AD, Thompson CC, Kaplan LM, Rubino F, Mingrone G, Becerra P, Rodriguez P, Vignolo P, Caplan J, et al. Endoscopic duodenal mucosal resurfacing for the treatment of type 2 diabetes: 6-month interim analysis from the first-in-human proof-of-concept study. Diabetes Care 201639 2254-2261.

Received in final form 11 April 2018

Accepted 18 April 2018

Accepted Preprint published online 18 April 2018 http://www.endocrineconnections.org https://doi.org/10.1530/EC-18-0094
()2018 The authors Published by Bioscientifica Ltd

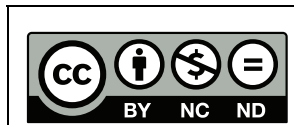

This work is licensed under a Creative Commons Attribution-NonCommercial-NoDerivatives 4.0 International License. 